\begin{tabular}{|c|c|c|}
\hline 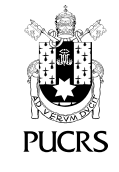 & $\begin{array}{l}\text { ESCOLA DE } \\
\text { HUMANIDADES }\end{array}$ & $\begin{array}{l}\text { Revista Digital do Programa de Pós-Graduação em Letras da PUCRS } \\
\text { Letrônica, Porto Alegre, v. 13, n. 1, p. 1-10, jan.-mar. } 2020 \\
\text { e-ISSN: 1984-4301 }\end{array}$ \\
\hline httn & $\mathrm{rg} / 10.15448 / 1984-4$ & \\
\hline
\end{tabular}

\title{
El imaginario de la nación desde el exilio en la obra y en la correspondencia de Clorinda Matto de Turner
}

\author{
O imaginário da nação do exilio na obra e correspondência de Clorinda Matto de Turner \\ The Imaginary of the Nation from Exile in Clorinda Matto de Turner's Work and Correspondence
}

Fanny Arango-Keeth
orcid.org/0000-0002-2554-1271

farangok@mansfield.edu

Recebido em: 11 nov. 2019

Aceito em: 11 nov 2019

Publicado em: 7 abr. 2020.
Resumen: Clorinda Matto de Turner parte al exilio desde Lima, Perú el día 25 de abril de 1895. La autora de la novela indigenista Aves sin nido llega y se instala en Buenos Aires, Argentina, ciudad en la que reside hasta el año de su muerte en 1909. A pesar de haber sido separada de la "fraternidad nacional", Matto de Turner sigue imaginando la nación y dando testimonio sobre ella tanto en su obra paraliteraria como en su correspondencia epistolar. En este artículo analizaremos la nación imaginada por Clorinda Matto de Turner en sus libros Boreales, miniaturas y porcelanas, Viaje de recreo y en las cartas de la escritora a Ricardo Palma. Palabras claves: Memoria histórica. Memoria social. Discurso autobiográfico. Nación imaginada. Matria.

Resumo: Clorinda Matto de Turner deixa Lima, Peru, em 25 de abril de 1895 para o exilio. A autora do romance indígena Aves sin nido chega e se muda para Buenos Aires, Argentina, onde vive até o ano de sua morte em 1909. Apesar de ter sido separada da "fraternidade nacional", Matto de Turner continua imaginando a nação e testemunhando sobre ela tanto em seu trabalho paraliterário quanto em sua correspondência. Neste artigo, analisaremos a nação imaginada por Clorinda Matto de Turner em seus livros, Boreales, miniaturas y porcelanas, Viaje de recreo e nas cartas do escritor a Ricardo Palma.

Palavras-chave: Memória histórica. Memória social. Discurso autobiografico. Nação imaginada. Matria.

Abstract: Clorinda Matto de Turner leaves Lima, Peru on April 25, 1895 to go into exile. The author of the indigenista novel Birds without a Nest arrives and settles down in Buenos Aires, Argentina where she stays until her death in 1909. Despite having been separated from the "national fraternity," Matto de Turner continues imagining her nation and writing her testimony about it in her paraliterary work and in her epistolary correspondence. In this article, we will analyze the nation that Matto de Turner imagined in her books Boreales, miniaturas y porcelanas, Viaje de recreo and in her letters to Ricardo Palma.

Keywords: Historical memory. Social memory. Autobiographical discourse. Imagined nation. Matria.
Los que no han salido de su patria, empujados por la mano del infortunio, los que no sintieron rugir la tempestad sobre su frente ni reventar la ola bajo la planta, ¿qué han de saber del dolor, qué de lo que importa un hogar hospitalario, que bajo su techo nos recibe con la dulce sonrisa del hermano y nos sienta a su mesa dándonos el nombre de amigo?

¡Yo sí lo sé!

Clorinda Matto de Turner, Boreales, miniaturas y porcelanas 


\section{Introducción}

La escritora, periodista y activista política peruana Clorinda Matto de Turner parte al exilio el dia 25 de abril de 1895. Según el relato de la historia oficial, el 15 de marzo del mismo año durante el segundo término constitucional de Andrés Avelino Cáceres como presidente del Perú, Nicolás de Piérola y sus montoneras ingresan a la ciudad de Lima y se produce un sangriento combate entre las fuerzas oficialistas y las montoneras. ${ }^{2}$ El 17 de marzo, Cáceres renuncia al cargo presidencial para que se establezca un gobierno provisional y de esta manera evitar un mayor derramamiento de sangre. Durante el período entre el 17 de marzo y el 25 de abril, se producen sucesivos atentados contra todo miembro de la sociedad civil que se identificara con el ideario político de Cáceres, en especial contra todos aquellos vinculados a su partido político. Esta circunstancia es la que determina que Matto de Turner opte por el autoexilio. Su destino final fue Buenos Aires, Argentina en donde vive hasta el dia de su muerte, el 25 de octubre de 1909.

Separada de la "fraternidad nacional" y ya en el exilio, la ilustre cusqueña no abandona su filiación con la nación que abandona por la fuerza. Es más, desde el destierro continúa cuestionando y desafiando el obrar inoperante del gobierno usurpador. Sin embargo, para poder seguir pensando una "nación" en la que se pudiera reformular y avanzar la recomposición del estado, la escritora opta por trascender las fronteras nacionalesy establecer un imaginario de nación, una "matria" más inclusiva, más panamericanista. Mary Louise Pratt sostiene que en el siglo XIX, cuando las mujeres eran separadas del orden social nacional, tendian a trascender las fronteras de sus propias naciones y crear un imaginario más abarcador en tanto sujetos politicos dentro del espacio público:
Hablando desde una perspectiva estructural, el desplazamiento de las mujeres de la fraternidad nacional produce, dentro del espacio nacional una inestabilidad radical, que se controla solamente gracias a un alto nivel de coerción ejercida sobre todo a nivel del cuerpo. Como habitantes sin ser plenamente miembros de las naciones, las mujeres que han tenido acceso a la esfera pública se han comprometido críticamente con los hábitos de pensamiento de los imaginarios nacionales. En la política, los movimientos femeninos autónomos han sido más frecuentemente internacionalistas y antimilitaristas, por ejemplo. En las letras, al menos antes de 1945, las intelectuales latinoamericanas pensaban no en términos de patrimonios nacionales (que típicamente han excluido su trabajo) sino más bien en términos mundiales o hemisféricos. (PRATT, 1993, p. 55)

El imaginario de nación creado por Matto de Turner en sus escritos de corte autobiográfico muestra un intenso compromiso del sujeto politico en efectuar el detallado seguimiento de los hechos sociohistóricos, políticos, culturales y artísticos que tenían lugar en el Perú. Este seguimiento inicial se transforma en una identificación plena de los procesos de construcción nacional en la memoria histórica de Matto de Turner a medida que la ausencia del territorio nacional se prolonga. En ese sentido, el objetivo de este artículo será analizar el discurso autobiográfico de Matto de Turner e identificar el recorrido de la memoria social e histórica de la escritora con respecto a la nación imaginada.

El corpus de estudio queda constituido por Boreales, miniaturas y porcelanas (1907). la correspondencia que la escritora mantiene ya en el exilio desde 1895 hasta 1902con el tradicionalista peruano Ricardo Palma y Viaje de recreo, obra publicada en forma póstuma en 1909. El discurso autobiográfico en este corpus muestra la nostalgia y ensoñación que generan la separación y la ausencia de la patria. En un acto de sustitución, la escritora convierte la nación

\footnotetext{
2 Carlos Wiesse describe este episodio histórico en Resumen de historia del Perú, publicado en 1908:
}

Piérola, venido del extranjero, a donde se había refugiado desde los primeros meses del periodo de Morales Bermúdez, para salvarse de las persecuciones políticas, se puso a la cabeza de las montoneras de Cañete, Yauyos y Huarochirí, a las que les dio una organización regular, avanzó sobre Lima en los primeros meses de 1895, y penetró en esta ciudad, defendida por las tropas de Cáceres, el 15 de Maro de aquel año. En ese dia y el siguiente se libró un sangriento combate entre ambas fuerzas y el 17 los contendientes ajustaron un convenio en virtud del cual Cáceres abandonó el poder, y se constituyó un gobierno provisional presidido por un Consejo de Ministros (p.265). 
imaginada en una matria ${ }^{3}$ por la cual transita entre el estado eufórico y el estado disfórico que genera el peregrinaje y el exilio. El análisis crítico, los recuerdos y las ausencias se afincan en la memora personal y social de Matto de Turner, un espacio privado que el sujeto autobiográfico inscribe su identidad como ocurre también en el caso que Isabel Allende describe en Mi país inventado: "las raices a falta de un lugar geográfico donde afincarse, lo han hecho en la memoria"(13). Analizar la memoria histórica y social que construyen el imaginario de nación en el discurso testimonial de Matto de Turner es un corpus indispensable para los estudios de género puesto que, como señala Leonor Arfuch, el mismo tiene como protagonista al sujeto femenino que habla en la primera persona:

Es bien reconocido el papel preponderante que ha tenido-y sigue teniendo-la autobiografía de mujeres-y, en general, la asunción de la primera persona en relatos de tinte confesional o testimonial-en la configuración del campo epistémico de los diversos feminismos, los estudios de género, identidad, agencia y experiencia.

[...] Lejos ya de la idea de una "experiencia femenina" que nos llevaría de retorno al esencialismo, se trata más bien de pensar las experiencias de las mujeres, con sus semejanzas y diferencias, como producto de lo que podriamos llamar, con Teresa de Lauretis (1992), las "tecnologias del género", es decir, la trama social, semiótica, epistemológica y crítica en la que se construyen sujetos generizados. (ARFUCH, 2013, p. 94-95)

\section{El camino al exilio}

Existen tres condiciones especificas que determinan el autoexilio de Matto de Turner: (1) como escritora, es objeto de una persecución social, política y religiosa a partir de la publicación de su novela Aves sin nido en 1889, (2) como periodista, su labor como directora/editorialista del semanario El Perú llustrado de 1891 a 1892 es cuestionada y (3) como miembro del Partido Constitucional liderado por Cáceres, es sancionada por la creación, publicación, dirección y edición del bisemanario Los Andes en 1892 en el que cuestiona la centralización del estado y la corrupción de los políticos de la época. Como sujeto político, Matto de Turner inscribe su posicionalidad en estas tres capacidades, cuestionando la ineficacia del gobierno republicano y la corrupción política, asi como también la falta de representación de los grupos marginalizados -el sujeto femenino y el sujeto indígena-en los retos de definición de la nueva nación republicana.

Recordemos que a diferencia del término "posición", la "posicionalidad" indica los valores ontológicos, existenciales y epistemológicos que pone en práctica el sujeto dentro del concepto que Algirdas Julien Greimas y Joseph Courtés definen como episteme. Identificar la posicionalidad del sujeto resulta ser entonces una tarea fundamental especialmente en el caso del discurso de corte autobiográfico en el cual se inscribe la identidad del sujeto subalterno. A partir de los nuevos estudios teóricos sobre discurso de clase, raza y género, es posible determinar las voces de las alteridades culturales o sociales y entonces estar en condiciones de reconstruir las prácticas culturales y politicas mediante las cuales los grupos subalternos cuestionan, resisten y subvierten los embates de las culturas hegemónicas4.

En el caso de la novela Aves sin nido, Matto de Turner cuestiona el centralismo, la ostentación del poder y la corrupción de los politicos en las comunidades andinas, el abuso contra el sujeto femenino, la explotación de los indígenas y la corrupción del clero. Cabe recordar que en el "proemio" de la novela, la escritora destaca su adhesión incondicional a las causas liberadoras de toda opresión:

\footnotetext{
3 Como hemos establecido con anterioridad en otros artículos, el uso del término "matria" deriva del estudio de Sandra Gilbert en su artículo "From Patria to Matria: Elizabeth Barrett Browning's Risorgimento." En este artículo, Gilbert agrega que una sustitución novedosa es asignar una identidad femenina, es decir un cuerpo femenino, a la representación simbólica de un país, sustituyendo el paradigma de patria (al cual se le asigna un valor connotativo masculino y por ende toda la paradigmática del hacer patriarcal) por el de matria (cuyo valor connotativo femenino se relaciona con la práctica sociohistórica del sujeto femenino).

4 En las notas del artículo "La reforma social y el discurso liberal en los editoriales de Clorinda Mato de Turner en el Perú Ilustrado (18891891" (220) planteamos que el concepto de posicionalidad implica un juicio y una voluntad de "ser" individual. Siguiendo la propuesta de Gloria Ladson-Billings en "Racialized Discourses and Ethnic Epistemologies": "todos definimos el mundo desde nuestras posturas sociales y culturales dentro de los contextos culturales, definidos por la raza, la clase, el género, la orientación sexual, la habilidad/inhabilidad, los estilos de comunicación cultural verbal y no verbal" [la traducción es nuestra] (p. 5-12).
} 
Repito que al someter mi obra al fallo del lector, hágolo con la esperanza de que ese fallo sea la idea de mejorar la condición de los pueblos chicos del Perú; y aun cuando no fuese otra cosa que la simple conmiseración, la autora de estas páginas habrá conseguido su propósito, recordando que en el país existen hermanos que sufren, explotados en la noche de la ignorancia, martirizados en esas tinieblas que piden luz; señalando puntos de no escasa importancia para los progresos nacionales, haciendo, a la vez, literatura peruana. (MATTO DE TURNER, 1994, p. 4)

Con respecto a sus editoriales como directora del periódico El Perú llustrado, la cusqueña identifica y trata los problemas que caracterizan a la sociedad peruana decimonónica5. Matto de Turner es acusada de "anticlerical" tanto por su agudo discurso liberal alentando la reforma social en los editoriales del semanario como por la publicación del relato "Magdala" del escritor brasilero Henrique Coehlo Netto el día 23 de agosto de $1890^{6}$. Antes de renunciar a la dirección del periódico, y en un gesto responsable y alturado, Matto de Turner pide disculpas al público lector en el editorial del 1 de noviembre de 1890 no sin antes dejar en claro que la razón por la que se exige su renuncia y se desencadena un nuevo ataque contra ella como sujeto político resulta ser el carácter liberal de su discurso editorial mediante el cual sigue identificando los problemas sociales que observa y describe en su primera novela:

No rehuimos las responsabilidades, pero a la vez pedimos, que sí no debe confundirse dos asuntos al parecer completamente diferentes: la publicación del artículo del señor Netto, Magdala, que hemos lamentado como desgraciado accidente, sobre el que llevamos nuestra sincera explicación ante el Jefe de lglesia, explicación rechazada, la actitud de los prelados contra el libro Aves sin nido, debemos reconocer que Magdala ha sido el pretexto, tal vez preparado por mano intencionada, y la novela el objetivo de toda persecución.
Liberada de los límites que la sociedad patriarcal y hegemónica le impusiera como directora y editorialista del semanario El Perú Ilustrado, y retomando su libertad de expresión, Matto de Turner establece su propia imprenta "La Equitativa" junto con su hermano David Matto, empresa en la que sólo emplea a mujeres. Como sujeto autogestionario, ahora capaz de publicar desde su propia imprenta, la ilustre cusqueña funda y publica el bisemanario Los Andes en cuyas páginas "piensa" la nación y la necesidad de reformar el estado peruano, denunciando y combatiendo decididamente la ineficacia de los políticos y estadistas de la época en cuanto al estado de la nación después de la Guerra del Pacíico. También, apoya la gestión política de Cáceres, como fiel militante del Partido Constitucional liderado por este héroe. Para contextualizar la labor periodística de corte subversivo y comprometido de la escritora, basta revisar el primer editorial de Los Andes publicado el dia 7 de setiembre de 1892. En este editorial Matto de Turner aboga por los intereses de la "patria" y por la necesidad de descentralizarla:

Ocupándonos de preferencia de letras, artes y ciencias americanas, la política tendrá nuestra colaboración; pero escuchando siempre el eco de la voluntad nacional y consultando con frialdad filosófica siempre, los intereses de la Patria sobre las pretensiones individuales. Nuestra labor se consagrará de un modo particular a estudiar las necesidades de las provincias y departamentos. (p.2)

La periodista comprometida no duda en hacer "visible" su identidad como sujeto político militante del Partido Constitucional durante 18 años, hecho que posteriormente desencadena su persecución:

Nosotros perteneciamos al número de los del orden. Serviamos al Partido Constitucional, por la

\footnotetext{
5 Por ejemplo, en el editorial de Los Andes del 24 de setiembre de 1892, Matto de Turner piensa los modos de representación política en una "nación culta", criticando el caso de su propia patria:

Comenzaremos a declarar la verdad de que un gobierno civil es el ideal de las naciones cultas, la aspiración racional de los Estados constituidos con vida propia. El gobierno civil, es pues realizable en un estado de civilización y orden perfectos. Será, por tanto, una de las aspiraciones de nuestro pais para cuando llegue a ser lo que todos anhelamos con orgullo de raza; pero al presente, que no existen hábitos de obediencia ni facultades de comando; ni las tendremos en muchos años [...] (p. 10). 6 El arzobispo de Lima censura la publicación por considerarla un sacrilegio y determina que su lectura constituye un "pecado mortal". De otro lado, el prolífico escritor Henrique Coehlo Netto (1864-1934), considerado el príncipe de la prosa brasileña en 1928, fue un escritor, político y profesor universitario, miembro de la Academia Brasileira de Letras.
} 
convicción de sus honrosas tradiciones, porque él nació bajo la bandera de la defensa del Perú contra el invasor, porque de su seno salieron los que sin cobardias desertoras ni apostasias calculadas, fueron siempre con el lema de la Patria. Nuestra lealtad para con el señor general don Andrés A. Cáceres era otro vínculo más para seguir al glorioso pabellón por él sostenido, y, si cometimos el pecado de mezclarnos en política, fue por el derecho que existe de pensar y de expresar el pensamiento. (p.23)

El constante "derecho que existe de pensary expresar el pensamiento" se observa en la activa participación de Matto de Turner durante la Guerra del Pacífico y en el proceso de la reconstrucción nacional. Con respecto a Piérola, la escritora denuncia públicamente cómo éste abandonó a la patria durante el periodo de la guerra y sugiere que su deseo de desestabilizar el gobierno con sus montoneras se debe a su accionar como agente chileno para perturbar el proceso de reconstrucción. La evaluación histórica de Piérola como sujeto histórico y político que ella efectúa en Boreales es sin duda sugerente:

Chile, que al lanzarse a la guerra de conquista lo hizo con plan meditado y programa definido, necesitaba asesinar esa Paz y buscaba el brazo para entregarle el corvo, y lo halló en el mismo que en San Juan y Miraflores le abandonó las puertas de la suntuosa capital desertando a carrera abierta hacia las criptas solitarias del interior. (p.13)

Asimismo, identifica y denuncia las fuentes de los aparatos ideológicos del estado que apoyan la toma de poder por parte de Piérola que "se fue a buscar elementos para la descomposición social en la morada de los chacales que envenenarían las fuentes de salud nacional, como la prensa, el pulpito y la cátedra universitaria" (BOREALES, p.14).

Como resultado de su visibilidad e influencia política como mujer visionaria y revolucionaria, escritora y periodista comprometida con la realidad nacional y activa militante politica del partido de Cáceres, Matto de Turner fue uno de los primeros sujetos políticos en ser atacados por
Piérola una vez asaltado el gobierno en Lima. Su casa y su imprenta7"La Equitativa” fueron asaltadas y vandalizadas, según su propio testimonio en la sección "En el Perú. Narraciones históricas" de Boreales, miniaturas y porcelanas:

Defendimos en la prensas, en nuestro semanario Los Andes, la política del partido constitucional, glorificamos el nombre del esclarecido ciudadano [Cáceres] que descolló en nuestra patria y fue llevado por segunda vez a regir los destinos del pais; lo hicimos por patriotismo sincero, con desinterés manifiesto y las consecuencias de nuestra inmiscuición las hemos arrostrado con serenidad, presenciando la destrucción de nuestro hogar, primero, después, la de nuestro taller de trabajo y por último aceptando el camino del extranjero para buscar el pan que no podiamos hallar en aquel suelo cargado de venganzas, de atropellos y de cuánto innoble puede producir la comandita del clericalismo con el pierolismo. (p. 23-24)

De igual modo, el nuevo poder político amenazó su vida y de la de su hermano el doctor David Matto, de su esposa y de sus dos menores hijos. Es a partir de esta coyuntura que Matto de Turner decide iniciar su autoexilio para proteger de este modo su propia vida y la de los suyos. Así nos lo explica en el testimonio "En el Perú. Narraciones históricas". También aclara que su autoexilio no enmarca "una derrota" sino una necesidad de revitalizar se cómo sujeto político, activo participante en el devenir histórico de su patria: "Permanecer en el Perú era algo más que difícil, la inspiración del espíritu nos señalaba la playa extranjera, no para ir a llorar la derrota, sino para vigorizarnos en la triple escuela del trabajo, de los viajes y del patriotismo. De lejos, cuánto se ama la familia y la patria!"(p. 65)

La insigne cusqueña parte hacia Argentina en el vapor Maipoel día 25 de abril de 1895. El itinerario la lleva primero a Chile hasta que finalmente se traslada a Argentina y se instala en Buenos Aires el 15 de mayo del mismo año, ayudada por escritoras, periodistas y amigos. La selección del destino final

7 En el discurso histórico y a la vez autobiográfico, Matto de Turner describe la destrucción de su "última fuente de vida que nos quedaba para la honrosa labro de buscar el pan con el sudor de la frente", la imprenta La Equitativa. Para demostrar que sus recuerdos corresponden con la realidad, cita al diario La Opinión del 8 de abril de 1895 en el que se lee la descripción del hecho:

La Opinión Nacional da cuenta de los luctuosos sucesos del 7 de abril, y al llegar a los asaltos y destrucción de propiedades dice: "La imprenta donde se editaba el bisemanario Los Andes sita en la calle de Lártiga, fue también asaltada violentandola puerta, rompieron un gran manparón de vidrios que daba entrada a los talleres, en éstos volcaron los cajetines, esparcieron los tipos e inutilizaron la máquina." (Boreales, p. 57) 
del exilio se relaciona muy especialmente con el origen del abuelo materno de Matto de Turner, el salteño Juan José Usandivaras ${ }^{8}$.

\section{El corpus}

Tanto en Boreales, miniaturas y porcelanas como en las cartas a Ricardo Palma y en Viaje de recreo, el valor del discurso autobiográfico radica en su carácter testimonial. Como sujeto político, Matto de Turner queda descentrada/separada de su nación, pero sin embargo no deja de "pensarla" y "vivirla" durante los trece años que vive en el destierro.

Como hemos indicado con anterioridad, en la sección "En el Perú. Narraciones históricas" de Boreales, miniaturas y porcelanas, la escritora efectúa un recorrido histórico evaluando la historia del Perú y los acontecimientos que desencadenaron su destierro. Su crítica sobre la tiranía es implacable:

Nuestra patria está purificándose en el crisol de las grandes hecatombes y de los grandes desengaños, NO NECESITA MÁS DE TIRANOS; guárdese el rifle y la espada para herir a los de fuera y en casa empúñese el arado que es fruto, la piqueta que es oro, y por doquiera, henchida el alma de férvida esperanza, resuene la voz del poeta soldado [...]. (MATTO DE TURNER, 1902, p. 64)

Una vez en Argentina, las declaraciones del sujeto autobiográfico con respecto al nuevo espacio de residencia y su observación de las prácticas culturales propias del mismo, muestran una aparente comparación con su nación "real". El espacio de los recuerdos en la memoria histórica de Matto de Turner es aquel en el que esboza su propio imaginario de la nación peruana, mientras que el espacio de valoración de la "nación" real se establece por comparación con la nueva matria que la recibe y en donde reside-nación que para la aguda observadora resulta haber trascendido con cierto éxito los limites patriarcales y hegemónicos impuestos al sujeto femenino en la suya. La valoración de la nación "que la recibe" es ostensible en el discurso epistolar del periodo inicial del exilio, como en el caso de la carta a Palma fechada el 9 de junio de 1895. En esta carta, la escritora declara su nuevo lugar de referencia y de pertenencia dentro de los espacios privado y público. Como mujer e intelectual, Matto de Turner no sólo es aceptada sino además admirada en la nación argentina.

\begin{abstract}
Aqui, he sido acogida con mucho cariño. Me encuentro como entre los míos. Si yo pudiera trasladar a David mis dos sobrinitos y la familia de usted que es todo lo que quiero, no pensaria en ausentarme. Todos nuestros amigos, escritores y periodistas me han atendido sin recomendación particular. Ahora estoy escribiendo en El Tiempo que me paga 10 centavos por linea y en La Producción Nacional que me da 10 pesos por columna. Con esto tengo para los extras.
\end{abstract}

De igual modo, destaca la dedicación al trabajo, "alto espiritu obrero" de la nación argentina, constante preocupación suya dentro del discurso periodístico:

Querido Palma. Este es un gran país. Qué ciudad tan grande y tan bella. Todo es grandioso y el espíritu obrero desarrollado en alto grado. De dia todo el menudo está en el taller, en la oficina, en el campo: de noche en el teatro. Por esto funcionan a la vez los 15 teatros que tiene la ciudad y se paga tan altos precios. En la opera un asiento cuesta 10 pesos y palco mil nacionales.

Debido a una enfermedad que la postra durante un período de dieciocho días, en la carta del 18 de noviembre de 1895 dirigida al tradicionalista, Matto de Turner expresa la añoranza, la nostalgia y el querer volver a su tierra. El imaginario de nación creado por la escritora tiene como "centro" a la familia nuclear:

Vea usted como vienen los contratiempos
cuando la estrella es mala. Yo que pensaba
distraer mi espíritu tan enfermo desde la muer-
te de mi adorado hermano, en cuya eterna
ausencia no puedo creer aún, no hago otra
cosa que pensar en él, en David y en los míos,
en la patria: He querido que David me mande
a mis sobrinitos para vivir del afecto de ellos,
pero, David no quiere desprenderse, creo que
para obligarme a volver por el cariño de ellos
y tal vez esto tendrá que suceder.

El deseo de seguir imaginando "la nación" la Lleva nuevamente a fundar y a dirigir un periódico, Búcaro Americano, en Argentina. En este proyecto, en tanto directora y editorialista,

\footnotetext{
8 En Boreales, miniaturas y porcelanas, Matto de Turner confirma esta filiación al llegar a la capital Argentina: Eran las ocho y medio de la mañana del 15 de mayo de 1895 cuando Buenos Aires la populosa, se presentaba amplia a nuestra vista. Convertido en realidad estaba, por fin, nuestro sueño acariciado desde la infancia, de visitar la patria de nuestro abuelo, don Juan José Usandivaras, la cuna de Juana Manuela Gorriti. (p. 97-98)
} 
y de acuerdo con el análisis de Gloria Hintze, la periodista muestra un constante diálogo con el público lector en general y con el público lector femenino en particular para definir el papel de la mujer en la construcción de la "nueva nación":

El proyecto de Matto sugiere un diálogo permanente con el público para impulsar la necesidad de definir conscientemente la nación. entre todos los agentes activos de la sociedad, incluida la mujer desde lo doméstico. También implica imaginar, desde estos espacios, el modo de representación y el modo de participación en una nueva imagen de nación. Clorinda Matto propone la presencia de una mujer convencida de su emancipación intelectual, capaz de generar una nueva eticidad nacional e integrando a todas las mujeres de Hispanoamérica. (HINTSE, 2000, p. 125)

En la fundación y dirección de este nuevo proyecto periodístico, el ideario de Matto de Turner resulta ser más panamericanista que nacionalista en concordancia con la propuesta de Pratt, pues como hemos visto, la intelectual latinoamericana del siglo XIX trasciende las fronteras de los estados republicanospatriarcales y hegemónicos-que la silencian y suprimen en tanto sujeto femenino para desarrollar movimientos mucho más inclusivos y abarcadores. En la carta del 1ro. de enero de 1896, la escritora le informa a Palma sobre la próxima publicación de Búcaro Americano: "El periódico que voy a fundar bajo la protección de varias sociedades de señoras creo que aparecerá el 15 del presente." Dos cartas después, en la misiva del 25 de mayo, al comentar un trabajo de neologismos en quechua que está efectuando para publicar en el periódico, la escritora comparte con el escritor de las Tradiciones peruanas, tanto el objetivo de la publicación como su percepción realista sobre el alcance del proyecto:

El resultado práctico de Búcaro no corresponde en nada a la idea que pueden formarse los que están convencidos de que en América la literatura es elemento negativo para el estómago. Si no me deja pérdidas continuaré pero si ha de ser preciso perder tiempo y dinero, no seré tan cándida para no colgar Búcaro así con todas sus flores y viñetas.

Muy a pesar de las cruentas vicisitudes del exilio, la filiación de Matto con su patria, así como su personalidad critica y visionaria perduran, como podemos observar en la carta fechada en Buenos Aires el 25 de Mayo de 1896. En esta muestra de discurso epistolar, destaca una secuencia discursiva que confirma que estando ausente de la matria, la escritora como sujeto político continúa su observación del acontecer histórico y social de la misma:

Entre tanto la situación de nuestro Perú cada dia peor. [...]

Bien me decia usted en una carta que ni Cristo compondrá nuestro país. La descomposición social es tan grande como la degeneración de la sangre. Desde esta distancia veo las cosas más claras y no cosecho más que la tristeza porque el futuro de nuestro país es peor que el de la Polonia.

[...]

Con el resto de los peruanos yo no dejo injerencia alguna.

Amézaga que ya debe estar en esa de regreso, dio una conferencia en el Ateneo con una concurrencia de veintidós personas inclusive el personal de la legación Ministro, Cónsul, secretarios atachés, etc.

Sainz que también dio otra conferencia tuvo diez y ocho oyentes. Yo no fui ni a una ni a otra. Sé estos pormenores por Vega Belgrano.

El sujeto autobiográfico comenta también la forma en que logró salvar su vida al partir hacia el exilio a Argentina. De igual modo, lamenta la muerte de su padre en la carta del 17 de julio de 1897. La pérdida del padre representa para ella la ausencia simbólica del espacio de origen, de bienestar y estabilidad que se concentra en dos figuras: el "sol" y el "centro" que corresponden al imaginario que la escritora elabora sobre la ciudad de Cusco, su ciudad natal. El "sol", "el centro" de la nación imaginada es el territorio del origen, la residencia del padre ausente y del dios tutelar de los incas. Este aspecto la conduce al espacio de la nostalgia:

Nuestra común amiga Urcina me ha mandado la estimable carta de usted, fecha 5 de junio próximo pasado, en la cual me manifiesta usted la parte que ha tomado en la nueva desgracia que viene a aumentar las tristezas de mi corazón en el que murió toda alegría junto con aquel llamado Daniel [su hermano], a quien ha seguido tan pronto mi querido padre. En todo pude pensar al emprender esta peregrinación atravesando por sobre el sepulcro de mi hermano y las cenizas de mi hogar y 
mi imprenta saqueados y destruidos por los regeneradores de mi patria, menos en lo que acaba de suceder. Sí, mi querido compadre. Se ha extinguido para mi ese sol que aún lo contemplaba lleno de luz y de calor paternal allá en esos risueños horizontes del Cuzco a donde dirigía con frecuencia la mirada del recuerdo y de la esperanza porque algún dia podría llegar a los umbrales paternos como el hijo pródigo y encontrar los brazos abiertos de mi padre. Pero él ya no existe sino entre estos seres invisibles que viven dentro de mi misma recibiendo la ofrenda de mis lágrimas.

Mary G. Berg en su introducción a Viaje de recreo enfatiza la importancia que este viaje tan deseado y planeado por Matto de Turner:

Viaje de recreo es una fusión de comentarios sobre los varios paises que Matto visitó, peo también incluye sus memorias de sus padres (de descendencia españolao, de su marido (inglés), de amigos de épocas diversas de su vida, de sus propias experiencias y pasiones. El libro cuenta sus impresiones de viaje, y sus observaciones, pero también relata cómo registró ella lo que vio, vivió, recordó y pensó durante estos meses tan importantes para ella. Ella explora las varias complejas verdades y ramificaciones de las verdades que observa en España, Inglaterra, Francia, Italia, Alemania y Suiza y las comenta desde perspectivas múltiples. Cruza todas las fronteras de definición de lo que constituye un relato de viaje, todas las fronteras entre observación e imaginación. ( $p . x x$ )

Durante este periplo europeo, Matto de Turner efectúa constantes comparaciones entre las diferentes culturas europeas con la peruana, la argentina y en general la andina. En su memoria social, su pertenencia a la nación imaginada está siempre activa como motivo de orgullo y de referencia. Con respecto a su gira europea, Matto de Turner comenta:

Mis pasiones son fuertes y definidas; arrancan de mi educación primaria bajo la sentencia del trágico to be or not to be. Detesto el agua tibia y los temperamentos indecisos; por eso amo y odio con llaneza y ardor, y lo que emprendo llega a la cima. Esta gira europea misma que estoy realizando, sola, cumplidos ya los cincuenta años de existencia, es manifestación comprobatoria del carácter cimentado en la sentencia shakesperiana, ser o no ser. Si no naci en Londres, naci en el Cusco, y me siento llena de orgullo legitimo. ¿Por qué no confesarlo? El disimulo de nuestras espontaneidades es hipocresía; yo la detesto del mismo modo que el agua tibia. (MATTO DE TURNER, 2010, p. 103)

Su preocupación por la necesidad constante de actualizar sus conocimientos sobre la enseñanza y la administración educativa, la lleva por ejemplo a visitar diferentes centros de instrucción pública en Londres para en el futuro poder beneficiar la instrucción pública en los dos países "de su afecto"9:

\begin{abstract}
[V]isitaré algunos edificios, fuera de la escuela de Westminster, que ya conozco; la Universidad de Londres, el Instituto imperial y el Museo de Historia Natural, que me orientarán por completo sobre locales, mueblaje y distribución de labor, cosas que tal vez pueda utilizar en servicio de aquellos dos países cuyo afecto se confunde en mi corazón como las aguas de los ríos que tributan al mar: Perú, Argentina. (MATTO DE TURNER, 2010, p.95)
\end{abstract}

Debido a su condición de escritora admirada internacionalmente y debido a la multitud de contactos profesionales que mantiene con intelectuales, periodistas y escritoras y escritores de la época, Matto es recibida eufóricamente en este viaje por los representantes de las delegaciones diplomáticas del Perú. El hecho de ser recibida por sus compatriotas en tierras extranjeras reproduce el efecto del reencuentro familiar dentro de la nación imaginada por la novelista.

En la misma obra, Matto de Turner comparte con sus lectores las visitas que considera trascendentales para la confirmación de la identidad visionaria y revolucionaria que siempre la caracterizó. Por ejemplo, "anatemizada" por la publicación del cuento "Magdala" de Coehlo Netto en El Perú Ilustrado en 1891, reestablece contacto con el escritor y lo visita en la escala que efectúa en Río de Janeiro en mayo de 1908. El escritor expresa su entusiasmo al verla, recordándole que ella "ha sufrido tanto en su patria" (p.9) a causa de "Magdala". La autora de Aves sin nido le responde que ese episodio de su vida "ya pasó" y que en su patria se le juzga ahora de forma diferente. (p.g)

De igual modo, desterrada por su adhesión al

\footnotetext{
9 Berg señala que el Consejo de Educación de la República Argentina envió a Matto de Turner a Europa para estudiar la educación de la mujer en ese continente (VIAJE DE RECREO, p. xxvi). En el libro, la escritora incluye una descripción de las visitas que efectúa con este propósito a diferentes instituciones de educación pública y privada y de educación superior.
} 
Partido Constitucional de Cáceres, se reencuentra con el héroe de la Breña quien la espera en su segundo regreso a la ciudad de París. En ese momento, Cáceres representaba al Perú en Italia con el carácter de enviado extraordinario:

Tengo la suprema alegría de encontrar a mi viejo amigo, el Señor General Andrés A. Cáceres. Al estrechar su mano creo tener en frente de mi a todo el Perú, aquella patria amada, como él, que es reliquia gloriosa de la nación, pues le ofrendó su vida y derramó la sangre de sus venas desde adolescente, cuando el año 1853 cayó herido en Arequipa, defendiendo las instituciones del país, más tarde en diferentes batallas contra los invasores, hasta la presente fecha en que sostiene con brazo vigoroso todavia el estandarte de la integridad del territorio y es jefe del legendario partido constitucional. En la actualidad representa al Perú en Italia, con el carácter de enviado extraordinario, y ministro plenipotenciario ante el Quirinal. Las vacaciones de que en la estación goza el cuerpo diplomático le dan tiempo para excursionar a Suiza en compañía de sus dos hijas y nietos; asi que está de tránsito en Paris. (p. 105-106)

El orgullo que la novelista cusqueña muestra por su nación es evidente cuando al entrar en el Museo de Historia Natural de Londres, Matto de Turner describe la ausencia de representación de las aves americanas, incluyendo en su discurso una palabra en quechua:

Recorremos sólo las principales colecciones, que con sus nombres indican la rama a que pertenecen. Geological and Paleontological, Mannualian, Botanical y Osteological. Con honda pena noto la ausencia de tanta belleza americana, especialmente en la sección de las avecillas. La variedad y el colorido de plumas que constituye una flora aérea en nuestros bosques, daría una idea a los europeos de lo que América ofrece en la familia de los volátiles y cantores. "Aqui tienen" digo a mi amiga--, su mirlo, sus ruiseñores, nosotros podriamos traerles gorjeos sublimes en la garganta del zorzal argentino y del chocllopokochi peruano". “Qué?", responde Miss sin poder pronunciar el nombre del pajarito Yo río orgullosa de haber dificultado la lengua de una inglesa con una frase del idioma de los incas, el rico quechua, que puro y expresivo conserva la región de la sierra del Perú, sobre todo el Cuzco, la antigua capital. (p.96)

\section{A modo de conclusión}

Se observa dos momentos en el imaginario de nación creado por Clorinda Matto de Turner en el destierro. Estos momentos coinciden con los períodos de salida inmediata de Perú y de llegada e instalación en la ciudad de Buenos Aires. La ensoñación y la euforia con respecto al imaginario de nación "idealizada" en la memoria personal de la escritora se centran en su grupo de pertenencia y se traduce en unconstante recuerdo de su familia inmediata, el padre en Cusco, su hermano David con su esposa y sus dos hijos y la familia de Palmaen Lima. El recuerdo eufórico se convierte en muchas instanciase en una nostalgia por la ausencia del hogar y del espacio familiar. El espacio familiar, sin embargo, se encuentra descentralizado de Lima y se ubica en la matria de origen de la escritora: la ciudad de Cusco.

De otro lado, la nación "real" sigue siendo cuestionada con respecto al abuso de poder y a la corrupción de los políticos que dirigen el país. Matto de Turner jamás deja de hacer presente su preocupación por la ausencia de representación de los grupos subalternos en los procesos de definición y de redefinición de la nación peruana. En el mismo sentido, Matto de Turner reconoce en el discurso autobiográfico que su ausencia de la matria es únicamente física, pues continúa política, social y culturalmente vinculada y activa dentro de la gestación de la nueva configuración de los poderes del estado. Por comparación con la nación argentina, el imaginario de nación que la escritora elabora sigue presentando los mismos problemas y desafíos de los que ella fuera testigo como activo sujeto político en la capital peruana. La matria argentina le brinda a la escritora el espacio de la afirmación y de reinscripción de su identidad sin los "anatemas" con los que fuera sancionada por el sujeto patriarcal y hegemónico en su Perú natal. Es también en el exilio que Matto recupera su perfil público en tres de los rubros en los que destacó siempre su actividad intelectual: el magisterio, el periodismo y la literatura.

Matto de Turner se reconcilia con su nación dentro de este imaginario en la etapa final de su estadia en Argentina antes de su muerte, hecho que se evidencia en el discurso testimonial de su obra póstuma, Viaje de recreo. Para ella, tanto Perú como Argentina reciben sus "afectos". La 
comparación constante entre Perú y Argentina y los países europeos que visita, demuestra su decisión de ser y pertenecer a las dos naciones y con ello confirma su identidad dentro de un imaginario de nación más abarcador. En relación con este aspecto, cabe recordar que el discurso testimonial incorpora estrategias de autoafirmación y auto representación como señala Arfuch:

El testimonio puede ser pensado como un tipo de autobiografía donde se unen-y se refuerzan-dos imaginarios de verdad y realidad: no sólo los hechos que tuvieron lugar sino también la propia experiencia que suscitan. Sin embargo, una vez más, no se trata de la expresión pura de lo vivido sino del despliegue del lenguaje en una configuración narrativa que involucra ciertas estrategias de autorrepresentación: cómo se construye el "yo" que narra, sus cualidades, atributos, circunstancias, valoraciones, la percepción del tiempo, su cronología-el orden de los sucesos que suele dispensar de la organización del relato--; los dichos y los hechos que se recuerdan y, por cierto, las marcas de género. (ARFUCH, 2010, p. 85)

La estrategia que la escritora cusqueña utiliza para la reconstrucción del "yo" en tanto agencia autobiográfica durante el destierro, se basa en elaborar un imaginario de nación en el que su práctica histórica y su actividad política no son afectadas por la sanción patriarcal que la separa y suprime del destino nacional. Por el contrario, ambas contribuyen a la validación de su identidad dentro del espacio extranjero.

Analizar el discurso autobiográfico escrito en el exilio sirve entonces para identificar las prácticas culturales de resistencia que las mujeres latinoamericanas utilizaron con la finalidad de subvertir los embates de la cultura hegemónica del siglo XIX y a la vez inscribir su identidad como sujetos políticos activos dentro del imaginario de la nación.

\section{Referencias}

ALLENDE, Isabel. Mi país inventado. Buenos Aires: Editorial Sudamericana, 2003

ARANGO-KEETH, Fanny. La reforma social y el discurso liberal en los editoriales de Clorinda Mato de Turner en el Perú Ilustrado (1889-1891). Boletín del Instituto Riva-Agüero 35, Lima, v. 37, p. 205-222, 2002. https://doi.org/10.1086/ahr/109.1.231
ARFUCH, Leonor. Memoria y autobiografia: exploraciones en los límites. Buenos Aires: Fondo de cultura económica, 2013

GREIMAS, Algirdas Julien y Joseph COURTÉSSemiótica. Diccionario razonado de la teoría del lenguaje. Madrid: Ed. Gredos, 1982.

GILBERT Sandra M. From Patria to Matria: Elizabeth Barrett Browning's Risorgimento. PMLA, IS. l.], v. 99, n. 2, p. 194-211, March. 1984. https://doi. org/10.2307/462161

HINTZE, Gloria. La revista Búcaro Americano y la presencia de la mujer en el periodismo literario. Revista de literaturas modernas, Cuyo, v. 30, p. 115-131, 2000.

LADSON-BILLINGS, Gloria. Racialized Discourses and Ethnic Epistemologies. Handbook of Qualitative Research, 2da. Edición. Thousand Oaks: Sage, 2000.

MATTO DE TURNER, Clorinda. Boreales, miniaturas y porcelanas. Buenos Aires: Imprenta de J. A. Alcina, 1902.

MATTO DE TURNER, Clorinda. Viaje de recreo. Edición de Mary G. Berg. Florida: Stockcero, 2010.

MATTO DE TURNER, Clorinda. Aves sin nido. Caracas: Biblioteca Ayacucho, 1994.

MATTO DE TURNER, Clorinda. Los Andes. Biblioteca Nacional del Perú.

MATTO DE TURNER, Clorinda. Correspondencia con Ricardo Palma. Biblioteca Nacional del Perú.

PORRAS BARRENECHEA, Raúl. El periodismo en el Perú. Lima: Instituto Raúl Porras Barrenechea, 1970. https://doi.org/10.24201/nrfh.v21i2.2853

PRATT, Mary Louise. Las mujeres y el imaginario nacional en el siglo XIX. Revista de Critica Literaria Latinoamericana, Lima, v. 19, n. 38, p. 51-62, 1993. https://doi.org/10.2307/4530672

\section{Dirección}

Fanny Arango-Keeth

31 South Academy St. Mansfield, PA, 16933

\section{Fanny Arango-Keeth}

Fanny Arango-Keeth recibió su doctorado en literatura latinoamericana de la Universidad Estatal de Arizona. Es profesora principal del Departamento de Inglés y Lenguas del Mundo de la Universidad de Mansfield en Pensilvania. Una de sus áreas de especialización es el estudio de la obra literaria y paraliteraria de las escritoras latinoamericanas del siglo XIX, en particular en la obra de la escritora peruana Clorinda Matto de Turner. Ha publicado varios artículos sobre el tema como "Del 'ángel del hogar' a la 'obrera del pensamiento': Construcción de la identidad sociohistórica y literaria de la escritora peruana del siglo diecinueve" en: Historia de las mujeres en América Latina. Murcia, 2003. 